\title{
Erratum to: Software Architecture
}

Patrick Donohoe

Carnegie Mellon University, USA

\section{Erratum to: \\ P. Donohoe (Ed.) \\ Software Architecture \\ DOI: $10.1007 / 978-0-387-35563-4$}

The book was inadvertently published with an incorrect name of the copyright holder. The name of the copyright holder for this book is: (c) IFIP International Federation for Information Processing. The book has been updated with the changes.

The updated original online version for this book can be found at DOI: $10.1007 / 978-0-387-35563-4$ 